\title{
The International Medical Society of Paraplegia at a Glance
}

On the occasion of the Silver Jubilee of the Journal of a Society it is customary to look at what has been accomplished by that Society. It appears however as appropriate to look ahead and set goals to be aimed for during the years to come. When looking back we not only should consider the history and the achievements of our Society but also the evolution of Spinal Cord Injury Medicine, paying first a tribute to some of the great names in this new discipline, its pioneers, without whom we should not be what and where we are today. Moreover we should always keep in mind that many others have helped our Society to become what it is, a respected worldwide acknowledged international Society of Specialists who take care and are caring for spinal cord injured patients, having contributed to the evolution and the establishment of the concept 'Paraplegiology'.

Sir Ludwig Guttmann founded our Society in 1961 and our journal Paraplegia in 1963. He revolutionised the care and outlook of those paralysed by injury to their spinal cord, and changed the methods of treatment of para- and tetraplegics throughout the world from one of neglect and despair to one of activity. We have been privileged to know and learn from this genius and natural leader who was called 'Poppa' by his patients-Dr Marc Maury, another French-born pioneer, once said that he did not know whether this meant 'father' or 'Pope', probably a little of both!

The U.S.A. also had their 'Pappy', Dr Ernst Bors, former chief of the Spinal Cord Injury Service in Long Beach, California, a contemporary and a friend of Sir Ludwig, and like him, a pioneer, a researcher, and a true scholar. And going back a little into history, to Dr Donald Munro from Boston, another authentic pioneer, who already in the 30s became reknowned for his then revolutionary conceptions about the rehabilitation of the spinal cord injured, not to mention his Bostonian pupil, Dr Herbert Talbot, who carried on the groundbreaking work through many medical publications and who became the second President of our Society, succeeding Sir Ludwig in 1969.

Our Society started quite small, almost like a brotherhood or a family affairwe were all Poppa Guttmann's kids, indeed!-growing into being an important and well-established Medical Society of 843 members from 57 countries. We went through our adolescence and puberty problems but we are coming of age, ready to overcome the difficulties of the future. Let us do it with the spirit of the man who biked in a hilly landscape: he cried when rolling downhill and laughed when pedalling hard to get uphill. When asked why he did not laugh going downhill and cry going uphill as most people would do, he said: 'I laugh going uphill because I know that I soon will have the easy ride down, and I cry going down knowing that I will soon have to work hard to get up.' So let us never be defeated by obstacles: there will be an easier ride later on! 
Some of the highest mountains which have been climbed successfully by our Society over the past years should be brought to mind here:

- the instalment of an autonomous IMSOP secretariat in Stoke Mandeville with its own secretary and business manager;

- the creation of financial, scientific and membership committees;

- the establishment of National Corresponding secretaries first in the U.S.A., and then in Japan and Spain, and now Italy concomitantly with the newly created Italian Medical Society of Paraplegia;

- the establishment of the Swiss Inter-Development Fund of the IMSOP which is presently sponsoring both the membership to 51 foreign physicians and free subscriptions to Paraplegia to 47 physicians and institutions abroad, especially in developing countries;

- the implementation for the first time in 1986 of two fellowships subsidised by the Swiss Fund to Dr Okonkwo, from Nigeria, and to Dr Amara, from Algeria.

As to the future, some of the most pressing goals to be reached can be summarised as follows:

-an enlargement of the scope of the Society aiming at further enhancing and supporting countries in development by promoting better care for the spinal cord injured through training and the setting up of new specialised spinal units or centres;

- the official recognition of the IMSOP by WHO as one of its full body NonGovernmental Organisations which should allow our Society to bring important spinal cord related subjects to the attention of the General Assembly of WHO delegates;

- the possible merging of the IMSOP into a Federation of National Paraplegia Societies at a time when there will be a sufficient number of them to justify such a major change of structure and policy;

- the further expansion of National Corresponding Secretaries of the IMSOP which should help to reinforce the importance of spinal cord rehabilitation in any given country;

-and last but not least the enlargement of the scope of the IMSOP membership which should aim more and more at getting colleagues whose primary specialty is not spinal cord injury but whose professional involvement is closely linked to problems relating to spinal cord physiopathology and rehabilitation. As of today it must be realised that most physicians primarily involved in the care of spinal cord injuries have already joined our Society. Moreover it cannot be expected that a great number of new spinal cord injury specialists will appear over the coming years because the 'profession' is already more or less saturated. Let us just consider for a moment how many new spinal injury units are going to be opened each year, not to mention the relatively small number of centres in the world where new positions will become available!

Therefore the only way to increase the IMSOP membership, to get better recognition and to be able to deliver better services to our patients is to recruit physicians in specialties other than spinal cord rehabilitation, such as orthopaedists, urologists, neurosurgeons and physiatrists whose professional involvement deals often but not exclusively with spinal cord patients. The larger the 
scope of these various specialties, the better the needs of our patients will be acknowledged and the paraplegic concept reinforced not from the inside but from the outside.

During these past 2 years I must say that I have given a high priority to this last challenging endeavour because I consider it to be of major if not vital importance for the continuous growth and steady maintenance of a high level of international recognition of our Society's goals and achievements aiming at improving the fate of the spinal cord injured, wherever he or she may be.

The most important goal, however, lies in our ability to discover what is to be found on the other side of the mountain, i.e., keeping an open mind for new ideas and looking for new horizons. Many challenges lie ahead of us. If we are to resolve them, let us work together. Then, and only then, will we be able to say as Sir Ludwig stated in the very first issue of Paraplegia in May 1963: 'Long may it flourish!'

Professor Alain B. Rossier

President 